\title{
Transforming an Organization into a Spiritual One: A Five- Pathway Integrated Framework
}

\author{
Khaled M. T. Banyhamdan ${ }^{1}$, Hussein Harrim $^{1}$ \& Mohi-Adden Yahya Al-Qutop ${ }^{1}$ \\ ${ }^{1}$ Business Administration Department, Faculty of Economics and Adm. Sciences, Applied Science University, \\ Amman, Jordan \\ Correspondence: Mohi-Adden Yahya Al-Qutop, Business Administration Department, Faculty of Economics \\ and Adm. Sciences, Applied Science University, Amman, Jordan. Tel: 962-795-573-233. E-mail: \\ alqutop@hotmail.com
}

Received: March 6, 2012

Accepted: April 6, 2012

Published: June 1, 2012

doi:10.5539/ijbm.v7n11p74

URL: http://dx.doi.org/10.5539/ijbm.v7n11p74

\begin{abstract}
This paper aims to provide a number of insights about the "what", "why", and "how" of workplace/ organizational spirituality, providing a clear and broader conceptualization and themes of the phenomenon. It presents an integrated framework leading towards building and maintaining a spirituality- based workplace. This framework encompasses five "core pillars" or "pathways": (1) organizational culture; (2) organization's mission, vision; (3) leadership; (4) human resource development; and, (5) organization structure and job design. Each can partially contribute to building a spiritual organization. But to build and maintain a truly spiritual organization, it requires to simultaneously and steadily proceed on all "pathways" or fronts".
\end{abstract}

Keywords: spirituality, spiritual organization, building sustainable spiritual organization: an integrated framework (conceptual research)

\section{Introduction}

Organizations of various types and sizes every where control the national wealth and resources, and deeply influence all domains and spheres of peoples' lives (economic, financial, social, educational, health, communication, recreational, etc.). Not less important, is the fact that most people every where spend a great part of their walking lives at work. Most adults organize their lives around work, and their sense of life is greatly shaped by their work. Every one defines himself and others in terms of his work.

Certainly, organizations have brought and provided many great blessings and outcomes to mankind. But no one can deny or ignore that organizations have bought so many unblessings and unfortunate outcomes and catastrophic disasters to employees, stakeholders, broader societies, environment and the whole world. To mention but few of these are: alienation, overconformity, inequality, depersonalization, personality fragmentation, unresponsiveness, inefficiency, overemphasis on rationality and technocracy (Scott, 1992:317-33), global warming, pollution, destruction of environment, exhaustion of resources, exploitation, toxic accidents, stresses, financial and economic crises, etc.

Organizations have been facing so many unprecedented challenges, changes, pressures and demands placed from many sources and levels- employees, organizational stakeholders, broader society, pressure interest groups and the whole world. Organizations are called to play a powerful agent of positive economic and social change and should contribute to economic and social progress, to human rights, dignity, health, welfare, education, technology, innovation, etc.

Management discourse and practices that have prevailed in organizations focused on maximizing profits, owners' interests, and short - run goals and objectives (Thaker, 2009) and stressing physiological, psychological and recently emotional well- being of employees as if they have no spiritual needs. In order that organizations can successfully meet the great challenges they face, they have to make a radical shift and transformation to new business model - a spirituality based organization. The topic has attracted a great number of scientists and researchers, and an increasing number of organizations have introduced spirituality- based practices. A new theory of workplace/ organizational spirituality emerging but not yet well - established. Hence, further research 
and inquiry, both theoretical and especially empirical, is still required.

\section{Workplace Spirituality: Definition and Dimensions}

Attempts to understand the phenomenon began in the early 1990s. Since then, many conceptualizations and definitions have emerged, which have differences in terms of emphasis, focus, dimensions/ components, and level of analysis, but there is a considerable overlap. Yet the topic is still a disputed and debatable one. According to Fry (2003), workplace spirituality is a new topic to organizational literature and is a topic with limited theoretical development.

Konz and Ryan (1999) defined spirituality as "the particular way the human person in all its richness, the relationship of the human person to the transcendent, the relationship between human persons, and the way to achieve personal growth are envisioned". According to Mitroff and Denton (1999), workplace spirituality "involves the offer to find one's ultimate purpose in life, to develop a strong connection to workers, and other people associated with work, and to have consistency (alignment) between one's core beliefs and the value of the organization. A clear and widely accepted definition was suggested by Ashmos and Duchon (2002), as follows: "workplace spirituality is the recognition that people have an inner life that nourishes and is nourished by meaningful work that takes place in the context of community". A rather similar definition was suggested by Milliman et al. (2003). "an organization is spiritual, they argue, to the extent that it serves as an outlet for its members to satisfy inner needs, to have a positive impact on society, to develop strong connections to others, and to have consistency between one's core beliefs and the values of the organization (Milliman et al. 2003). A different definition by Giacalone and Jurkiewicz $(2003,13)$, " a framework of organizational values evidenced in the culture that promote employees' experience of transcendence through the work process, facilitating their sense of being connected to others in a way that provides feeling of completeness and joy". An elaborate empirical definition was proposed by Kinjerski and Skrypnek (2004:37):

Spirit at work involves: engaging work characterized by a profound feeling of well- being, a belief that one engaged in meaningful work, that has a higher purpose, an awareness of alignment between one's values and beliefs and one's work, and a sense of being authentic, a spiritual connection to something larger than self, a sense of community characterized by a feeling of connectedness to others and common purpose, and a mystical or unitive experience characterized by a positive state of energy or vitality, a sense of perfection, transcendence and experience of joy or bliss.

Marques (2006) conceptualized work place spirituality as follows:

Spirituality in the workplace is therefore the awareness that interconnectedness, respect, and recognition are not limited to our private environment, but also very much applicable to all those with whom we work......it is, therefore, essential that the experience of performing our duties should be one that is rewarding to all involved, hence, providing ourselves and those we deal with in the workplace with feeling of trust, belonging, meaning, and fulfillment in all areas that we consider important toward the quality of our lives.

Rego and Pina e Cohna (2008) argue that a spiritual organization is one "that provides meaningful work that instils a feeling of purpose and fosters a sense of connection and positive social relations with coworkers, and that provides workers with the ability to live integrated lives".

It is clear that no agreed on definition of workplace/ organizational spirituality exists. According to Laabs (1995), "It is much easier to explain what spirituality is not than it is to define what spirituality in business is". Such difficulty is not surprising given the intensely personal nature of spiritual experience, and that spirituality does not mean the same thing to all people. The various definitions and conceptualizations have differences in terms of emphasis, focus, dimensions and level of analysis, but there is considerable overlap. Milliman et al. (2003) indentified three dimensions of workplace spirituality: meaningful work, sense of community, and alignment with organizational values. The "holistic development model" of workplace spirituality, developed by Lips-Wierma (2003), encompasses six themes: developing and becoming self; unity with others, serving others, expressing full potential, and spiritual coherence, the themes are interconnected". Sheep (2004), based on a review of the literature, point that a conceptual convergence occurs in four recurring themes: a self- workplace integration, meaning in work, transcendence of self, and personal growth/ development of one's self at work. Duchon and Plowman (2005), proclaim that "most definitions include the notions of meaning, purpose, and being connected to others".

On the other hand, workplace spirituality has been conceptualized as either passive and static, having trait- like qualities, or as dynamic, that is having capacities and abilities that are evolving and interactive (Giacalone and Jarkiewiz, 2003). Krishnakumar and Neck (2002) examined three perspectives of workplace spirituality: 
intrinsic- origin view; religious view and existentialist perspective. According to them, intrinsic-origin perspective defines workplace spirituality as something originating from the inside of the individual. Religious view sees spirituality as tied to one's religious affiliation. The last perspective (existentialist) argues that spirituality involves existentialist questions; such as: "what is the meaning of my work?" and "why am I doing this work?"

As for the level of analysis, some definitions focus on the organizational-level, and others focus on the individual level. Workplace spirituality at the organization level refers to an organization culture guided by mission statements, leadership, and business practices that are socially responsible and value- driven, that recognized the contributions employees make to the organization, and that promotes individual spiritual development and wellbeing (Ashmos and Duchon, 2000; Mitroff and Denton,1999).

At the individual level, spirituality refers to the desire of employees make to express all aspects of their being at work and to be engaged in meaningfull work (Ashmos and Duchon, 2000; Mitroff and Denton, 1999), and to reach one's full potential (Krishnakumar and Neck, 2003; Neck and Milliman 1994).

Kolodisky, Giacolone and Jurkiewicz (2009) added a third level of conceptualization; an interaction of the individual and organization levels. The authors argue that conceptualizing workplace spirituality in this way parallels the concept of person- environment fit. When fit is strong between worker's values and his perceptions of the organization's values, better work outcomes will result.

It can be said that each of the above- mentioned conceptualizations and definitions, and others, of workplace spirituality is incomplete but not inaccurate. Based on the brief review of the literature on this phenomenon, it can be concluded that a spirituality- based workplace world have the following themes and notions:

- A truly meaningful job/work.

- Inclusion, belonging, collectivism: people working together in community toward commonly held vision and goals.

- Employees have a higher purpose and greater sense of responsibility, to contribute to the welfare and betterment of community, society, and meaningful world.

- Integration/ alignment of personal values and beliefs with organizational/ professional values and job performance.

- Integrating personal growth and long- term character development and learning with job performance.

- Recognize that all people have creative capacities and potentials that need to be unleashed and nurtured, and promoting expressing/reaching one's full potential.

- Help employees develop a sense of "calling" or "transcendence" and experience of joy and bliss.

- Emphasizing "sustainable growth and development" and full awareness of limited resources, genuine concern for saving and protecting our earth planet and what lives on it.

- Promoting vocation: help organizational members develop a sense of transcendence- of having a call through one's work (vocational), share ownership of organizational values, and experience of joy and bliss.

\section{Forces and Challenges Driving for Spiritual Organization}

Several forces, changes, challenges and demands, at the individual, organizational, societal, environmental and global levels, have urged and pushed for the fast growing interest in workplace spirituality. Employees are looking for ways to counterbalance the stresses and pressures of a turbulent pace of life; contemporary lifestylessingle- parent families, geographic mobility, the temporary nature of jobs, new technologies that create distance between people- underscore the lack of community that people feel; people are looking for involvement and connection; aging baby boomers are reaching mid-life and looking for something meaningful, in their lives, something beyond the job; others desire to integrate their personal life values with their professional lives (Robbins and Culter, 2005: 62; Burack,1999, Wagner-Marsh and Conley,1999).

Spirituality is undeniable a human need for many, if not all, people (Hart and Brady, 2005), and workplace spirituality is a "reality" that must not be ignored by society and organizations. Many employees look for the satisfaction of their spiritual needs, i.e. to be unique, to be useful, to be understood by others, and as to understand how they fit into greater context (Strack et al, 2002). Pfeffer (2003) summarizes the human goals that people seek in their workplace as follows:

- Interesting work that allows learning and development and that provides a sense of competence and mastery; 
- Meaningful work that instills some feeling of purpose;

- A sense of connection and positive social relation with coworkers; and

- The ability to live an integrated life, so that the work does not clash with the essential nature of the worker and his desire to live as a human being.

Konz and Ryan (1999) argue that "the shift in the nature of work is leading to a shift in the nature of organizations. The nature of work appears to have changed fundamentally.... people are searching for meaning in work that transcends more economic exchanges between isolated, autonomous individuals. Organizations are slowly evolving from arenas of purely economic and social activity into places of spiritual development". Mor Barak and Levin (2002) proclaim that "Research over the past two decades indicates that exclusion from organization networks and from important decision- making processes is one of the most significant problems facing today's diverse workforce".

Other reasons for this steadily growing interest in workplace spirituality include:

A rising general public interest in spirituality in response to increasing levels of spiritual disorientation from isolation, disconnection and a lack or loss of meaning in life, dramatic change in the nature of work resulting from increasing globalization and a shift from the industrial age to the information age, which has resulted in longer work hours, and increased expectations for productivity, accompanied by less job security due to downsizing and layoffs and increased work- life conflict (Leigh,1997; Brondt, 1996; Adams and Benzer,2000; Ashmos and Duchon, 2000; Kinjerski and Skrypnek,2006). Describing the organizational environment, Marques (2006) states: "The prevailing stressful atmosphere seems to be more a rule than an exception in corporate America..... and that the average organizational environment, by definition, leans towards toxic than toward healthy". According to Giacalone et

al. (2003), "the most riable arguments for the growing interest in workplace spirituality are "society seeks solutions to ease tumultuous social and business changes, that profound change in values globally has brought a growing social consciousness and spiritual renaissance, and that growing interest in eastern philosophies has surfaced spiritual yearnings overall". The spiritual revival in the workplace is attributed, according to Fernand and Gross (2006), Dente et al. (2005) to a broader religious awakening in America. Thaker (2009) proclaimes that current managerial discourse and practices are dominated by neo- liberalism, which translates to individual self- interest". Thaker adds that "modern business challenges can't be met with knowledge - based tools, technical strategies and processes dealing with the physical realm. What is needed, is a spiritual model of business ...... The number of corporations integrating ethics, values, and human, social, environmental and global concerns into their culture is skyrocketing".

A similar view expressed by Fry and Slocum Jr. (2008) as they proclaim " One of the greatest challenges facing leaders today is the need to develop new business models that accentuate ethical leadership, employee well being, sustainability and social responsibility without sacrificing profitability, revenue growth, and other indicators of financial performance". They add "Top managers need to simultaneously maximize the so- called "triple bottom line "or" People, Planet, Profit"; they suggest that this can realized through the development of spiritual leadership and workplace".

During the last few years, the world has witnessed several dramatic challenges, changes and crises. In 2008, a devastating financial crisis paralyzed United States of America, which soon extended to most countries throughout the world. The crises have brought many sadful and unfortunate economic, financial, social and even ethical, outcomes and have severely impacted peoples' lives everywhere.

The year 2011 have witnessed unexpected and unprecedented challenges and events. The so-called "Arab Spring" with uprisings and mass demonstrations and protests have swept over many Arab countries, bringing to an end several regimes and governments. In the same year, a number of European Union countries have suffered catastrophic "public debts" crises which have very serious bad impacts on peoples' lives in these and other countries.

Last, but not least of the challenges is the so-called "Wall Street Movement". In October, 2011 protesters and demonstrators marched New York street heading to occupy wall street. On the following day(s), protests and demonstrations spread to so many capitals and cities in USA and many other countries around the world. Protesters and demonstrators voiced severe criticisms and accusation of capitalism, world financial system, globalization, corrupt and greedy businesses and banks for such worse, miserable and sadful economic, financial and social conditions of peoples' lives. Millions of people have lost their homes, others have lost their jobs, health and education have been steadily declining, social injustice, inequity, global warming, environment 
destruction, the widening gap between the rich and the poor, within the same country and between rich and poor countries, suppression, oppression, dehumanization, and such.

An important reason which has accelerated the fast growing interest and research inquiry in workplace spirituality is the increasing evidence of the many significant rewards and benefits of workplace spirituality, which will be discussed in the following part.

\section{Organizational Spirituality: Potentials and Limitations}

\subsection{Benefits and Potentials}

In order that employers and managers will be willing and motivated to build and maintain spiritual workplace, it requires demonstrating that such spirituality is compatible and aligned with organizational mission, vision, goals and performance. Neck and Milliman (1994) proclaim that spirituality can positively affect employee's and organizational performance in many ways:

First, Spirituality can lead individuals to experience consciousness at a deeper level, thereby enhancing their intuitive abilities, which are related to personal and organizational productivity. Second, spirituality based intuition can also facilitate employees to develop more purposeful and compelling organizational vision, which can increase innovation. Third, organizations which offer spirituality - oriented work goals provide opportunities for employees to experience greater personal growth and development, which can significantly increase employee energy and enthusiasm. Fourth, spiritual - based values can enhance teamwork and employee commitment to the organization.

In discussing the legitimacy of the association between spirituality and organizational performance, Fry (2003) states:

By understanding the vision of the organization and being empowered with the autonomy to act as they see fit, participants have an experience of competence in that, through their work they are making a positive difference in other people's lives which in turn enriches their own. It is such outcomes, ultimately based in the satisfactions that result from work performed as if it were a calling, that will result in higher levels of reduced stress, the same organizational goals most often reported as affective outcomes of organizational research.

Empirical research in workplace spirituality has been recently growing but still scarce compared to theoretical research. This is due mainly to the lack for agreed on definition and measurement instrument(s). Empirical studies found that spirituality in organizations is positively associated with productivity; reduce turnover, employee satisfaction, team performance, organizational commitment, creativity and organizational performance (McCormick, 1994; Brandt, 1996; Leigh, 1997; Mirvis, 1997; Conlin, 1999). Organizations that encouraged spirituality experienced higher profits and success (Mitroff and Denton, 1999; Turner, 1999). According to Mitroff and Denton (1999, p.91) "No organization can survive for long without spirituality and soul. Well-known writer Thompson $(2000$, p.19) found that the more spirited companies outperformed the others by $400-500 \%$, in terms of net earnings, return -on- investment, and shareholder value ". Thompson added that a workplace without spirituality can ultimately result in high absenteeism, high turnover, high stress associated with work deadlines, and depression. Fawcett et al. (2008) reported that an inspiring spiritual workplace improves productivity, service quality and retention.

A study conducted by Duchon and Plowman (2005) revealed that work unit performance is associated with work unit spirituality; work unit performance is greater in work units that enable a spiritual (or spirit- friendly) climate. Also, the study found that work unit spirituality is associated with the leader's ability to enable the worker's inner life, sense of meaningful work, and community.

Lips-Wiersma and Verkatarman (2006) provided a number of compelling examples of empanies that had integrated corporate sustainability and spirituality, achieved superior performance evidenced by key financial parameters. A study conducted by Fry and Slocum Jr. (2008) found that higher levels of spiritual leadership subsequently had higher levels of spiritual well-being that in turn positively impacted organizational commitment, productivity, and sales growth. According to them there is evidence that workplace spirituality programs not only lead to beneficial personal outcomes, such as increased positive human health and psychological well-being, but they also deliver improved employee commitment, productivity and reduced absenteeism and turnover. There is mounting evidence that a more spiritual workplace is not only more productive, but also more flexible and creative and a source of sustainable competitive advantage (Fry and Slocum Jr. 2008). Fawcette et al. (2008) reported that an inspiring spiritual workplace improves productivity, service quality and retention.

Other finings reported by empirical studies carried in non-Westen settings (Jordan, Malaysia and India) revealed: 
a strong association between workplace spirituality on one side and corporate social and ethical responsibility, and employees morale (Najm and Al-Rifa'e, 2008), workplace spirituality has an important role to play as an aide to leadership development and leadership effectiveness (Abdullah et al., 2009), and that workplace spirituality is positively associated, to a considerable degree, with the attitudes of employees: job satisfaction, job involvement, and organizational commitment (Pawar, 2009).

\subsection{Undesirable Results of Workplace Spirituality}

Although workplace spirituality has definitely brought many blessings and positive outcomes, it is not without criticism. Giacalone et al. (2003) pointed that "spirituality can have both desirable and undesirable effects on organizational performance. For example, negative spiritual traits such as authoritarianism is grounded in selfish and egoistic values and pride. Furthermore, there may be unforeseen costs as well as benefits of employing a spiritual employee. For example, if we found that a spiritual employee held higher ethical standards than those of other employees, those higher standards could also lead the employee have higher expectations for what constitutes appropriate ethical behavior..... such standards could prove costly, both in terms of time and price". Fernando and Gross (2006) proclaim that the practice of workplace spirituality poses several significant challenges to business managers:

1) Managers may embrace a spiritual approach to exploit their members without resulting personal spiritual awareness or commitment.

2) Driven by a permanent need to maximize profits, for-profit organizations spousing workplace spirituality are likely to fall victim to the practice of pseudo-spiritual practices (organizational hypocrisy).

3) Workplace spirituality seems susceptible of being adopted without a genuine commitment to an authentic practice because it can be used as tool to seek legitimacy with the stakeholders of the organization. Robbins (2008) point to the following problems and reservations: legitimacy problem: do organizations have the right to impose certain spiritual values on their employees; economic problem: dedicating spirituality to make more profit; as a source for conflict and discrimination, a source for managerial control.

\section{Building and Maintaining Spiritual Organization}

An Integrated Framework

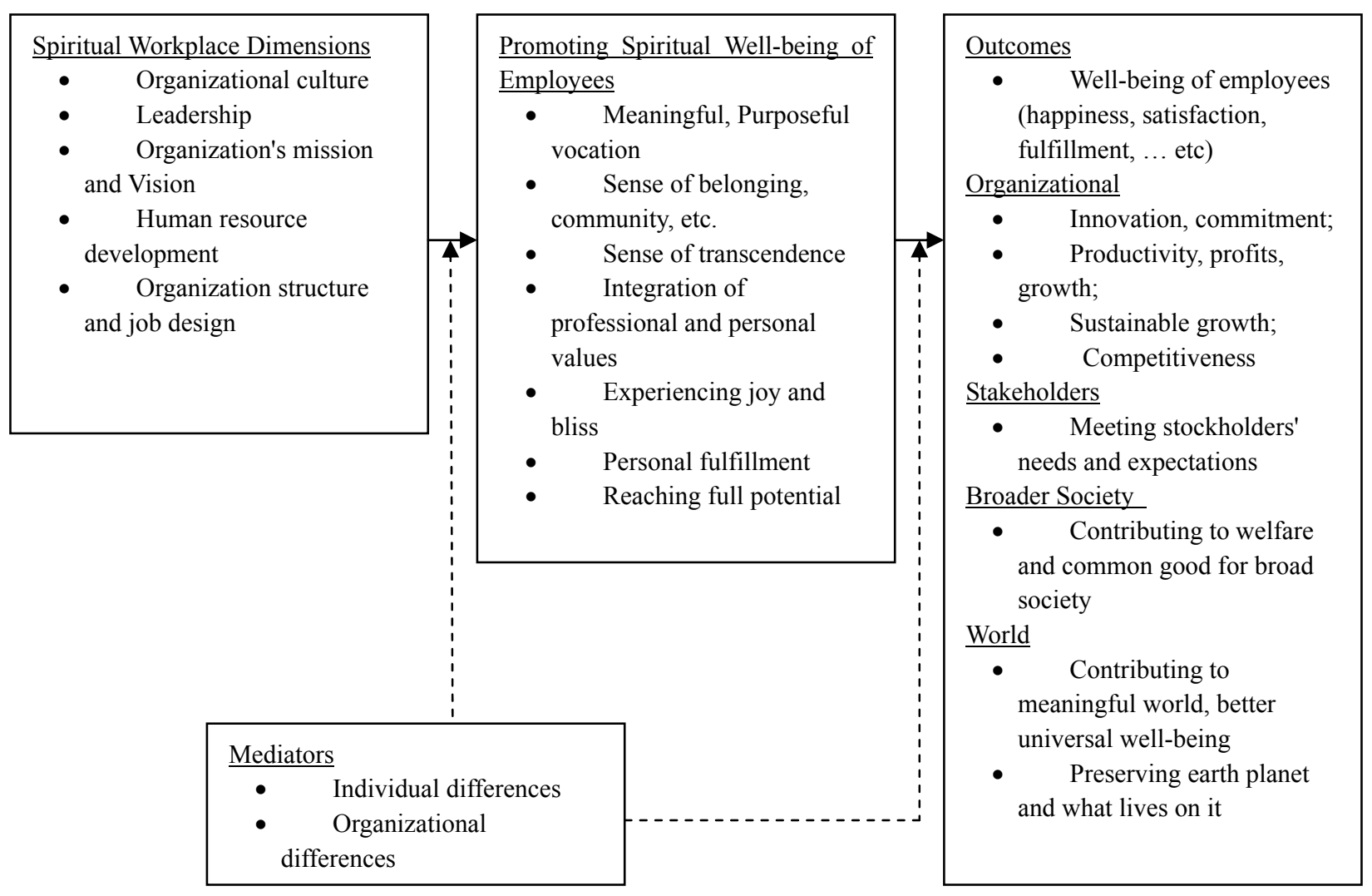

Figure 1. Framework of spiritual workplace/ organization transformation 
No doubt that it is a very challenging, demanding and complex task and never an easy, simple one, for a number of reasons. First, there is no agreed on definition and measurement. Second, spirituality is a multi-faceted; multi-dimensional phenomenon. Third, the prevailing organizational total workplace context (structural, design, social, cultural, etc) is very unfavorable and constitutes a counterforce against transforming organizations towards more spiritual ones. However, the literature, both theoretical and empirical, provides invaluable approaches and insights which, once consolidated and integrated, can make a broad framework to guide serious endeavors seeking building spirituality at workplace. Following, is a brief discussion of the core pillars" or "pathways" of this framework/ model (figure 1).

\subsection{Organization Culture}

Organization culture is considered a key and principal pillar in building and maintaining spiritual organization. The literature provides several frameworks/ models of organizational culture characteristics. Giacalone et al. (2003) call for "establishing a social/ organizational culture based on altruistic love whereby leaders and followers have a genuine care, concern, and appreciation for self and others, thereby producing a sense of membership and feel understood and appreciated".

Jurkiewicz and Giacalone (2004) assert "It is plausible that organizations that express spirituality as defined by the presence of certain values and cultural traits (e.g. trust, benevolence, justice, respect, humanism, meaningful work, hope, dignity and honesty) create an environment where integration of the personal and professional selves is possible, engaging the whole person in the work process".

A third perspective is suggested by Robbins and Coulter (2005) who state that spiritual organizations have the following cultural characteristics:

- $\quad$ Strong sense of purpose (meaningful purpose).

- Focus on individual development.

- Trust and openness (among members of the organization, and between members and customers, suppliers, etc).

- Employee empowerment.

- Toleration of employee expression.

Another more elaborate framework of spiritual-based culture is provided by Fawcett et al. (2008). According to the authors, an organizational culture should have the following dimensions and factors:

- Core values: community, teamwork, accomplishment, self-esteem, balance.

- Organizational climate: affirmation, belonging, competence (which should support the values).

Workplace attributes: Job design, empowerment, respect, equity and collegiality which promote individual development as well as proactive and supportive workplace climate. Fry and Slocum Jr. (2008) suggest a framework not so different from Jurkiewicz and Giaclone's framework. They point that "When altruistic values of respect, fairness, honesty, care, compassion and the like are integral parts of an organization's culture, a culture of trust emerges" (Fry and Slocum Jr. 2008). Vallabh (2010) proclaims that spirituality is integrated in organizational culture, and looks at spirituality as a cultural phenomenon. According to Vallabh (2010) an organizational culture has four cultural traits: involvement, consistency, adaptability, and mission.

It is clear that writers do not agree on a particular set of cultural traits of spiritual-based organization culture. The various frameworks, though they have differences, they have a considerable overlap. Rather than seeing them as conflicting, they are complementary.

Recently, unethical conduct and behaviors by organizational members-employees, managers and executives-have been growing fast, worldwide. There is a critical and urgent need for an organization culture that is ethically based, advocating high ethical standards, respecting and protecting human rights, universal moral principles, justice and such.

\subsection{Leadership}

The terms such as "spiritual leadership", "moral leadership", "authentic leadership", and "ethical leadership" proclaim that the implementation of a spiritual mindset in the workplace as being a leadership responsibility (Marques, 2006). Konz and Ryan (1999) stress the multi-faceted role and impact of leader ship as follows: Organization's leaders are called to play a significant role as guide in transforming organization into spiritual one. Spirituality of leaders is the key to maintaining the spirituality at workplace. The leader's spirituality should guide what they do, so through their actions, they bring their spirituality to life. The key to maintaining an 
organizational culture is the philosophy and values of the leaders. Leader's spirituality also influences the selection and socialization of employees, and through mission statement. Well-known lendership scholar, Bennis (2002) calls for the need for leaders to "follow your spirit" and create meaningful work for others as well as a sense of community at work". Similarly, Pfeffer (2003) urges organizational leaders to assume management practices that enrich human spirit by building values. He argued that building spirit at work requires the following leadership practices: (1) emphasize mission and values over shareholder profits; (2) encourage autonomy and decision making responsibility; (3) use self-managed teams; (4) use collective forms of rewards and recognition; (5) let people be who they are and use and develop their gifts and skills; (6) provide a way for people to fulfill their family and other social obligations; (7) drive fear and abuse out of the workplace. Wiles $(2005$; 195) suggestes the following leadership strategies to increase spirit at work: (1) tolerance, respect, and acceptance of other religious and spiritual organizations; (2) promoting a pluralistic, non-coercive, and non-degrading working environment; (3) discussion of religious and spiritual harmony in the workplace.

Fry (2003) developed the theory of spiritual leadership within an intrinsic motivation model that incorporates vision, hope/faith and altruistic love. Fry \& Slowm Jr. (2008) state that the following key processes are essential to spiritual leadership:

1) Creating a vision wherein leaders and followers experience a sense of calling so that their lives have meaning and make a difference.

2) Establishing a social/ organizational culture based on the values of altruistic love whereby leaders and followers have a sense of membership, feel understood and appreciated, and genuine care, concern and appreciation for BOTH self and others.

All scholars firmly stress the significant role of organizational leaders in building and maintaining spiritual workplace, but they suggest different approaches that can be seen as all accurate and complementary.

\subsection{Mission and Vision Statement}

A clear compelling vision is very important. This vision should vividly portray a journey which, when understood, will give one a sense of calling, of one's life having meaning and make a difference... The vision, coupled with the organization's purpose (its reason for existence), and mission (what the organization does and who it serves), work in concert to define the organization's core values (Giacalone et al., 2003). A similar, but more clear and elaborate view of the organization's mission is expressed by (Konz and Ryan, 1999):

The mission statement of an organization details the philosophy, and values of the organization, it explains the goals and the acceptable means for achieving the goals; philosophy, values, goals and means are spelled in language understood by organizational members... the mission statement can serve as the enunciated culture of an organization, because all members of the organization have agreed on the meaning of the terms or ideas used in the statement.

Konz and Ryan (1999) stress the importance of "developing a very clear and understandable organizational mission statement. If it uses terms that are not understandable by the organization's members, then the organization is having difficulty in maintaining its spirituality".

Yes, it is important that an organizational mission and vision statement should be clear, understandable and acceptable by employees, but what is also important is what the mission and vision statement says (content).

Organizations need to simultaneously maximize the so-called triple bottom line, or, "People, Planet, Profit"... Simultaneously optimize employee well-being, social responsibility, organizational commitment, and organizational performance (Fry \& Slocum Jr., 2008). They add, "Organizations should adopt sustainable models adopting sustainable business strategies that have a positive economic, social and environmental impact". Since organizational culture plays a critical role in building a spiritual workplace, mission and vision statements need to institutionalize a culture based on a altruistic values of love, respect, fairness, honesty, care, compassion and the like. (Fry \& Slocum Jr., 2008).

Thaker (2009) defines an organization's purpose as creating value/ wealth (economic, social, and environmental) for world large. Based on the Practical Compassion framework developed by Lips-Wiersma and Nilakant, Thaker proclaims that mission statements should reflect a commitment to pursue business activities and decisions that contribute to the common good and keep in mind social justice and environmental protection (Thaker, 2009).

\subsection{Human Resource Development}

Workplace spirituality is a learnable behavior (Ashmos \& Duchon, 2000). Therefore Human Resource 
Management should try to include it in their training and development programs for all employees, the new and the established employees. Fry (2003) proclaims that "a failure to invest in the knowledge and skills of the employees can stifle the organizational long-term capabilities... Competence in conjunction with affirmation and belonging is an indispensable piece of inspiring workplace climate". According to Fawcette et al. (2006), helping workers gain the skills needed to succeed in their assigned responsibilities is the best way to motivate adventurous, inquisitive, enterprising and enthusiastic behavior, which can be contagious in an inspiring culture". Neck \& Milliman (1999) call for "thought self-leadership (TSL) training to help create constructive pattern thoughts and enhance employees' perceptions about work and help them develop a more purposeful vision of work, and eventually gain more spirituality in their work life". Moreover, without development, training and empowerment employees can't express or reach their full potentials.

Human development should not be limited to the skills and capabilities relevant to specific job assignments. Instead, it should go beyond this to include skills, capabilities, knowledge, values and attitudes which benefit the greater whole and contribute to the betterment of other's lives at the community, national, and even worldwide levels. Hence, organizations should recognize the great value of knowledge and learning, and provide enough opportunities, facilities, grants, paid and non-paid leaves for training/ learning, tuition refund, mentoring, promote from within" policies, and encourage, support and reward employees to constantly learn, grow and develop intellectually, emotionally, ethically and spiritually (the whole person should develop and grow). A very closely associated with human development is employees empowerment. Empowerment is a multi-dimensional construct that encompasses four dimensions: (1) meaning (value of work goal or purpose); (2) self-determination (autonomy); (3) impact (the degree to which the individual's behavior makes a difference and influence on work outcomes); (4) competence (self-efficacy). (Spreitzer, 1995; Thomas and Velthouse, 1990).

Empowerment is closely associated with spiritual leadership, personal growth and development, and reaching one's full potentials. Neck and Milliman (1994) argue that "A critical factor in whether spiritual-based management practices result in improved performance involves empowering employees with the capability to participate in developing and implementing the organizational vision". The reason for this, say Neck \& Milliman, (1994) is that a key aspect of spirituality is that all people should seek to reach their full potential and empowering employees is the only way individuals can attain their fullest sense of growth and contribution".

Empowerment is also closely linked with teamwork, which provides individuals with the sense of interconnectedness and community, and also the opportunity to experience responsibility, and achievement. True empowerment can significantly contribute to human development which is essential to build spirituality at workplace. True liberty, argues Thaker (2009), implies that employees at all levels have liberty and may participate or have a say in strategic decisions and are encouraged to take part in company's management, social responsibilities, and all other activities at an appropriate level. True liberty, adds the author, permits employees to develop and explore that which is of benefit for all greater whole, and not only confined to the specific job assigned to an employee. Empowerment and participation need very supportive and favorable organizational culture, leadership, and organization design.

\subsection{Organization Structure and Job Design}

"The present deep structures, say Konz an Ryan (1991), are highly resistant to cultural change which is very essential to convert organizations into spiritual ones. The deep structures already in place do make it easier to maintain a culture than to change it". Developing and maintaining the "core pillars", discussed aboveorganization culture, organization mission and vision, spiritual leadership, human development empowerment-that are essential to build and maintain spiritual organization, require organic, adaptive, learning organization, boundaryless structure with low specialization, low formalism, high decentralization, and smooth free, open communications in all directions. Cross-functional and cross-hierarchical teams should be widely used. It requires an organizational structure that enhances, supports and encourages knowledge building and sharing throughout the whole organization. Constant, intense and close contacts and communication with all stakeholders and broader society are very essential. In brief, organizations attempting to move towards more spirituality, have to adopt structures that enhance, facilitate, support and reinforce whatever efforts and changes the organization undertakes to make the shift successful.

Job design has gained more importance and interest, especially from scholars and researchers in human resource management. Research reveals that well-designed jobs can enhance motivation, satisfaction, and performance of employees (Gary and Rastogi, 2006). A well-known model for job design is the job characteristics model (JCM), which identifies five core job characteristics: skill variety; task identity; task significance; autonomy and feedback. These job characteristics are followed by three critical psychological states: experienced 
meaningfulness; experienced responsibility; and knowledge of results. A sixth characteristic, namely: interaction, was added by (Ivancevich et al., 1999; 252) which requires using team-based rather than individual-based design. Interaction at work enhances sense of belonging and interconnectedness, which is an important component/aspect of spiritual workplace. Other workplace attributes that are favorable to building organizational spirituality include:

- $\quad$ Flexible work schedules, compressed work schedules, job sharing, telecommuting must be allowed within organizations.

- Reasonable workload and hours, minimum travel and relocation demands, in order that employees have leisure to spend with the family and engage in various sports, recreational, social and other activities at the family, community, national and even global levels.

- Amicable, friendly-like supportive environment.

- Safe, wholesome, comfortable surrounding favorable to health, with minimum risk of illness or injury and health hazards, and reasonable work stresses.

- On-site exercise facilities, gym, sports area education for health nutrition, fitness, and healthier life-style, etc.

One final point about the "core pillars" of building a spirituality -based organization is that they are interdependent and interacting. Such interdependence yields an effect and impact much greater than the sum of the impact of each individual factor. An important thing that must be stressed, is the fact that individual and organizational differences play a mediating role in the process of transformation of an organization into a spiritual one.

\section{Conclusions and Future Research}

Recently, human spiritual well-being has been widely discussed and debated by an increasing number of scientists and researchers. Concurrently, research and inquiry in organizational spirituality has attracted a great number of writers from different disciplines, including organization and management science. Consequently, many different conceptualizations and perspectives of workplace spirituality have been proposed. The conceptual framework presented in this paper, hopefully, would provide a modest contribution to the literature on this phenomenon. It is an attempt to present an integrative concise knowledge base which, hopefully would help managers and organizations to better appreciate and understand spirituality oriented workplace context and practices. The framework provides five "core pillars" or "pathways" to build and maintain spiritual organization, those are: organization culture, organization's mission and vision, leadership, human resource development, organization structure and job design. The interaction of implementing two or more of these "pathways" would, definitely, bring much greater impact on transformation of an organization into spirituality- based one.

The model has significant promise to promote and enhance the spiritual well-being of organizational members and ultimately improves the quality of their total lives, not only professional ones. Also, the model has great potential to improve and enhance organizational performance, profitability, growth, innovation, meet expectations of organizational stakeholders, develop high corporate ethical standards and active corporate social responsibility, sustainable growth, and ultimately contribute to better and meaningful world and earth planet.

It is anticipated that the model will arouse and stimulate more research, both at the theoretical and empirical fronts. Scientists and researchers are invited to carry out further research on several fronts to establish the validity of this model before it should be widely applied as a model fostering systemic organizational transformation into spirituality-based one. Further empirical research should examine the impact of each pathway of the model, and the impact of the interaction of two or more pathways on the various themes of organizational spirituality.

Other important areas that need further research are: the mediating role of individual and organizational differences; and to make a clear, conceptual distinction between workplace spirituality variables and workplace religion theories and constructs in order to further advance emerging workplace spirituality theory building. Moreover, researchers would investigate organizational hypocrisy-pseudo workplace spirituality so that both managers and employees are aware of and can avoid it. Finally, more research is expected and needed to investigate "whether", and "how" individual and organizational differences mediate the relationship between the "pathways" and their effects on building a spiritual organization.

\section{Acknowledgement}

The authors are grateful to the Applied Science Private University, Amman, Jordan, for the financial support 
granted to cover publication fee of this research article

\section{References}

Abdulla, Abdull Ghani K., Alzaidiyeen, N., \& Aldaraba, I. (2009). Workplace spirituality and leadership effectiveness among educational managers in Malaysia. European Journal of Social Sciences, 10(2), 304-316.

Adams, T., \& Bezner, J. (2000). Conceptualization and measurement of the spiritual and psychological dimensions of wellness in college population. Journal of American Health, 48(4), 165-74. http://dx.doi.org/10.1080/07448480009595692

Ashmos, D., \& Duchon, D. (2000). Spirituality at work: a Conceptualization and measure. Journal of Management Inquiry, 9(2), 134-145. http://dx.doi.org/10.1177/105649260092008

Bennis, W. G. (2002). Crucibles of leadership. Harvard Business Review, 80, 39-48.

Bennis, W. G., Duchon, D., \& Plowman, D. (2005). Nurturing the spirit at work: impact on work unit performance. The Leadership Quarterly, 16, 807-833. http://dx.doi.org/10.1016/j.leaqua.2005.07.008

Brandt, E. (1999). Workplace trends: corporate pioneers explore spirituality. Human Resource Magazine, 41(4), 82-87.

Bromn, R. B. (2003). Organizational spirituality: the skeptic's version. Organization, 10(2), 393-400.

Burack, E. H. (1999). Spirituality in the workplace. Journal of Organizational Change Management, 12(4), 280-291. http://dx.doi.org/10.1108/09534819910282126

Delbeq, L. A. (1999). Christian spirituality and contemporary business leadership. Journal of Organizational Change Management, 12(4), 345-349. http://dx.doi.org/10.1108/09534819910282180

Dente, E., Higgins, E., \& Wharff, D. (2005). Spirituality and leadership: an empirical review of definitions, distinctions and embedded assumptions. Leadership Quarterly, 16(5), 620-629.

Duchon, D., \& Plowman, D. (2005). Nurturing the spirit at work: impact on work unit performance. The Leadership Quarterly, 16, 807-833. http://dx.doi.org/10.1016/j.leaqua.2005.07.008

Fawcette, Stanley et al. (2008). Spirituality and organization culture: Cultivating the ABCs of an inspiring workplace. International Journal of Public Administration, 31, 420-438. http://dx.doi.org/10.1080/01900690701590819

Fernando, Mario, \& Gross, M. (2006). Workplace spirituality and organizational hypocrisy: The Holy Water-gate Case 2006. Retrieved from http://ro.uow.edu.au/commpapers/159

Freshman, B. (1999). An exploratory analysis of definitions and applications of spirituality in the workplace. $\begin{array}{llll}\text { Journal of Organizational Change } & \text { Management, 12(4), 327. }\end{array}$ http://dx.doi.org/10.1108/09534819910282153

Fry, L. W. (2003). Toward a theory of spiritual leadership. The Leadership Quarterly, 14, 693-727. http://dx.doi.org/10.1016/j.leaqua.2003.09.001

Fry, L. W., \& Slocum Jr., John (2008). Maximizing the triple bottom line through spiritual leadership. Organization Dynamics, 37(1), 86-96.

Garge, Pooja \& Rasting, R. (2006). New model of job design: motivating employees' performance. The Journal of Management Development, 25(6), 572-587.

Giacalone R. et al. (2005). From advocacy to science: the next steps in workplace spirituality research. Retrieved from http://www.traleton.edu=fry/SLTPaloutzianFinal.rtf

Giacalone, R., \& Jurkiewicz, C. (2003). Toward a science of workplace spirituality, in Giacalone R. et al. (Eds), The Handbook of Workplace Spirituality and Organizational Performance. New York, M. E. Sharp.

Hancock, P. G. (1997). Citizenship or vassalage? organizational membership in the age of unreason. Organization, 4(1), 93-111. http://dx.doi.org/10.1177/135050849741006

Hart, D., \& Brady, F. (2005). Spirituality and archetype in organizational life. Business Ethics Quarterly, 15(3), 409-428.

Ivancevich, et al. (1997). Management: Quality and Competitiveness (2nd ed.). Boston, McGraw-Hill.

Jurkiewicz, C., \& Giacalone, R. (2004). A values framework for measuring the impact of workplace spirituality 
on organizational performance. Journal of Business Ethics, 49(2), 129-142. http://dx.doi.org/10.1023/B:BUSI.0000015843.22195.b9

Kinjerski, Val \& Skrypnek, Berna. (2006). Measuring the intangible development of the spirit at work scale. Paper Presented at the sixty-fiftth Annual Meeting of the Academy of Management, Atlanta, GA.

Kolodisky, et al. (2010). In Vallab, Priyanka, workplace- spirituality relationship with organizational culture and effectiveness. Paper presented at AIMS International Conference on Value-based Management.

Konz, Gregory, \& Ryan, Franscisca. (1999). Maintaining an organizational spirituality: no easy task. Journal of Organizational Change Management, 12(3), 200-210. http://dx.doi.org/10.1108/09534819910273865

Krishnakumar, S., \& Neck, C. (2002). The "what", "why" and "how" of spirituality in the workplace. Journal of Management Psychology, 17(3), 153-164. http://dx.doi.org/10.1108/02683940210423060

Laabs, J. (1995). Balancing Spirituality at work. Personnel Journal, 74(9), 60-62.

Leigh, P. (1997). The new Spirit at work. Training and Development, 51(3), 26-41.

Lips-wiersma, M., \& Nilakant, M. (2008). Practical compassion: towards a critical spiritual foundation for corporate responsibility. In Biberman, Terry and Tischler, Len (Eds.), Spirituality in Business: Theory, Practice, and Future Directions (Palgrave Macmillan).

Lips-Wiersma, M., \& Nilakant, V. (2006). Purpose beyond profit: toward a spiritual foundation for corporate social responsibility. Paris: European Bhaj Business Formula. Retrieved from www.ebbf.org/publications. Accessed on February, 12th, 2008.

Lips-Wiersma, Marjolein. (2003). Making conscious choices in doing research in workplace spirituality utilizing the "holistic development model" to articulate values, assumptions and dogmas of the knower. Journal of Organizational Change Management, 16(4), 406-425. http://dx.doi.org/10.1108/09534810310484163

Marques, Joan. (2006). The spiritual worker: an examination of the ripple effect that enhances quality of life in and outside the work environment. Journal of Management Development, 25(9), 884-896. http://dx.doi.org/10.1108/02621710610692089

McCormick, D. (1994). Spirituality and management. Journal of Management Psychology, 9(6), 5-8. http://dx.doi.org/10.1108/02683949410070142

McGee, J. (1998). The emergence of "secular" corporate spirituality. Paper presented at the Academy of Management, San Diego, CA.

Milliman, J. et al. (1993). A model of hierarchical advancement in Korean Chaebols: a review and research agenda. Human Resource Management Review, 13, 293-330. http://dx.doi.org/10.1016/1053-4822(93)90003-M

Milliman, J. et al. (2003). Workplace spirituality and employee work attitudes: an exploratory empirical assessment. Journal of Organizational Change Management, 16(4), 426-447. http://dx.doi.org/10.1108/09534810310484172

Mirvis, P. (1997). Soul Work in Organizations. Organization Science, 8(2), 191-199. http://dx.doi.org/10.1287/orsc.8.2.192

Mitroff, I. (2003). Do not promote religion under the guise of spirituality. Organization, 10(2), 375-382. http://dx.doi.org/10.1177/1350508403010002011

Mitroff, I., \& Denton, E. (1999). A spiritual Audit of Corporate American: A Hard Look at spirituality, Religion and Values in the Workplace (1st ed.). San Francisco, Jossey-Bass Publishers.

Mitroff, I., \& Denton, E. (1999). A Study of spirituality in the workplace. Sloan Management Review, 40, 83-92.

Mor Barak, M., \& Levin, A. (2002). Outside of the corporate mainstream and excluded from the work community: a study of diversity, job satisfaction and well-being. Community Work and Family, 5(2), 133-157. http://dx.doi.org/10.1080/13668800220146346

Najim, N., \& Al- Rifa'e, Gh. (2008). Spirituality in the workplace: field study of a sample of firms in Amman, Jordan. Jordan Journal of Business Administration, 4(1), 64-88.

Neck, C., \& Milliman, J. (1994). Thought self-leadership: finding spiritual fulfillment in organizational life. Journal of Managerial Psychology, 9 (6), 9-16. http://dx.doi.org/10.1108/02683949410070151

Pawar, Badrinaryan S. (2009). Individual spirituality, workplace spirituality and work attitudes: an empirical test 
of direct effects. Leadership and Organization Development Journal, 30(8), 759-777. http://dx.doi.org/10.1108/01437730911003911

Pfeffer, J. (2003). Business spiritual management practices that sustain values. In Giacalone, R and Jurkiewicz, C. (Eds.), The Handbook of Workplace Spirituality and Organizational Performance. New York, Sharp (29-45).

Rego, A., \& Pinae Cohna, M. (2008). Workplace spirituality and organizational commitment: an employee work attitude. Journal of Organizational Change Management, 21(1), 53-75. http://dx.doi.org/10.1108/09534810810847039

Robbins, S., \& Coulter, M. (2005). Management (5th ed.). New Jersey, Pearson Prentice-Hall Int.

Roy, M. L. (1992). The Emerging new paradigm in business. In Renesch, J. (Ed.), New Traditions in Business. San Francisco, Berret-Koehler Publishers.

Scott, W. R. (1992). Organizations: Rational, Natural and Open Systems. Englewood Cliffs, N, J., Prentice-Hall Inc.

Sheep, M. L. (2004). Nailing down gossamer: a valid measure of the person- organization fit of workplace spirituality, best paper proceedings of the sixty-third annual meeting of the Academy of Management, B1-B6.

Spreitzer, G. M. (1995). Social structural characteristics of psychological empowerment. Academy of Management Journal, 39(2), 483-504. http://dx.doi.org/10.2307/256789

Spreitzer, G. M. (1995). Psychological empowerment in the workplace: dimensions, measurement and validation. Academy of Management Journal, 38(5), 1442-1464. http://dx.doi.org/10.2307/256865

Strack, G., Fottler, M., Wheatley, M., \& Sodomak, P. (2002). Spirituality and effective leadership in healthcare: is there a combination? Frontiers of Health Services Management, 18(4), 3, 17.

Thaker, Kejur B. (2009) Approaches to spirituality in business. Journal of Human Values, 15(2), 185-198. http://dx.doi.org/10.1177/097168581001500208

Thomas, K., \& Velthouse, B. (1990). Cognitive elements of empowerment in an interpretive model of intrinsic task motivation. Academy of Management Journal, 15(4), 666-681.

Thompson, W. D. (2000). Can you train people to be spiritual? Training and Development, 54(112), 18-19.

Turner, J. (1999). Spirituality in the workplace. CA Magazine, 132(10), 41-42.

Vallabh, Priyanka. (2010). Workplace spirituality-relationship with organizational culture and organizational effectiveness. Paper Presented at AIMS International Conference on Value-based Management.

Vogel, David. (2005). The Market of Virtue: the Potential and limits of CSR. Washington, D. C., Brooking Institute Press.

Wagner-Marsh, F., \& Conley, J. (1999). The fourth wave: the spirituality-based firm. Journal of Organizational Change, 12(3), 292-302. http://dx.doi.org/10.1108/09534819910282135

Wiles, B. (2005). Religion and the workplace: pluralism, spirituality, and leadership. Journal of Interdisciplinary Studies, 17(1/2), 195-196. 